\title{
Ultrasound surveillance in endoluminal laser treatment for varicose veins
}

This article was published in the following Dove Press journal:

Journal of Vascular Diagnostics

25 October 2013

Number of times this article has been viewed

\section{Gianfranco Varetto \\ Paolo Garneri \\ Claudio Castagno \\ Valentina Molinaro \\ Simone Quaglino \\ Matteo Ripepi \\ Emilio Benintende \\ Lorenzo Gibello \\ Stefano Zan \\ Luigi Contessa \\ Ugo Bertoldo \\ Pietro Rispoli}

Vascular Surgery, Department of Surgical Sciences, University of Turin, Turin, Italy
Correspondence: Pietro Rispoli University of Turin, Department of Surgical Sciences, Division of Vascular Surgery, Molinette Hospital, Corso A M Dogliotti 14, Torino, Italy

Tel +39 01 I 6335297

Fax +390116335102

Email pietro.rispoli@unito.it
Abstract: Venous ultrasonography is an indispensable tool in minimally invasive surgery for the treatment of varicose veins. However, the criteria for defining preoperative imaging parameters, outcome monitoring, and follow up are not well characterized. In this retrospective study, we reviewed the ultrasound periprocedural parameters and the outcomes in 274 patients (280 limbs) after endoluminal laser treatment, at early ( $<30$ days) and late (1-60 months) follow up. Treatment failure was defined as complete recanalization of the saphenous trunk, thigh perforator vein insufficiency, and recanalization of the proximal saphenous trunk. Judicious patient selection correlated with favorable outcome at the follow-up ultrasound examination.

Keywords: follow-up, chronic venous disease, intravenous, obliteration

\section{Introduction}

Venous ultrasonography is an indispensible tool in endoluminal laser treatment (ELT) for varicose veins, and it constitutes the first step in this procedure. ${ }^{1-3} \mathrm{~A}$ typical procedure begins with echo color Doppler ultrasound (US) imaging of the diseased vein to trace its location. This step then allows the physician to determine the skin puncture site where the needle will be inserted in the vein, as well as to control the insertion and endoluminal progression of the wire and the sheath and the placement of the laser fiber in the proximity of the saphenofemoral junction. The progression of the fiber inside the vessel can also be visualized, to control the laser effect on the venous wall. Perivenous tumescent local anesthesia can also be performed under US surveillance. Finally, during follow up, echo color Doppler is useful to confirm the stable and durable efficacy of treatment, to investigate the etiology of recurrence, or to evaluate the progression of chronic venous disease. ${ }^{4}$ The aim of this study was to define standard criteria for monitoring outcomes after ELT.

\section{Materials and methods}

Between April 2005 and September 2010, in the Division of Vascular Surgery, University of Turin, Italy, 274 patients underwent duplex US examination prior to ELT for great saphenous trunk insufficiency. Echo color Doppler (MyLab ${ }^{\text {TM }} 25$; Esaote, Genoa, Italy) was performed immediately before surgery, with the patient in an orthostatic position, and a reflux was considered pathologic if lasting longer than 500 milliseconds. All the procedures were done by two surgeons. A 18G needle was used for percutaneous puncture of the vein; then, a $5 \mathrm{~F}$ catheter was inserted over a 0.018 inches guide wire, with US-guided advancement of the catether tip to the internal 
saphenous arch (just below the superficial epigastric vein and within $1.5 \mathrm{~cm}$ of the saphenofemoral junction). ELT was performed with an $810 \mathrm{~nm}$ diode laser wavelength (Diomed $30 \mathrm{~W}^{\circledR}$; Diomed Inc.). All patients gave written informed consent in accordance with Helsinki declaration.

The procedure was performed under local anesthesia (approximately $100 \mathrm{~mL}$ of saline plus $200 \mathrm{mg}$ lidocaine), administered subcutaneously to induce tumescence around the long saphenous vein segment. Monitored anesthesia care, using midazolam $(0.02 \mathrm{mg} / \mathrm{kg})$ and remifentanil $(0.025 \mathrm{mcg} / \mathrm{kg} / \mathrm{min})$, was administered during the procedure.

The treatment power energy was $12 \mathrm{~W}$, and the mean power was $70-80 \mathrm{~J} / \mathrm{cm}^{2}\left(100 \mathrm{~J} / \mathrm{cm}^{2}\right.$ in the first $3 \mathrm{~cm}$ from the internal saphenous arch). All evident varicosities were concurrently treated with phlebectomy.

Early follow-up examination included duplex US scanning at 1, 7, and 30 days; late follow up was performed at 3,6, and 12 months after the procedure, then annually. All follow-up examinations were performed by the same vascular surgeon.

The Italian Society of Vascular Diagnostics guidelines recommend follow-up at 1, 6, and 12 months and then annually after venous procedures. Closer follow up (1-7 days) after ELT will usually reveal early complications (deep venous system involvement) and permit the documentation of treatment efficacy. ${ }^{5}$ Because most complications appear within 3 months after treatment, an echo color Doppler control examination is warranted at this time. ${ }^{6}$

Early follow-up US examination investigated for endothermal heat-induced thrombosis and deep venous thrombosis. The imaging findings indicating favorable outcome were:

1. At the saphenofemoral junction:

a. Patency and absence of thrombotic occlusion of the common femoral vein

b. Occlusion of the saphenous trunk

c. Residual saphenous stump $<3 \mathrm{~cm}$ without reflux

d. Patency of the tributary vessels of the saphenous trunk in the common femoral vein

2. At the saphenous trunk:

a. Appearance of a nonechoic lumen suggesting thrombosis

b. Appearance of an echoic lumen, not compressible and without reflux.

Late follow-up examination checked for either evident recurrent varicosities (classified as clinically visible or palpable varicosities more than 3-4 $\mathrm{mm}$ in diameter) or echographic evidence of recurrence.
In the present series, after ELT ablation, three types of reflux were found:

1. Recanalization of a previously occluded saphenous trunk

2. Neoreflux in an accessory saphenous vein

3. Thigh perforator vein insufficiency and recanalization of the proximal saphenous trunk.

Independently of clinically evident varicosities, favorable outcomes were defined as the complete obliteration of the great saphenous vein (GSV) after laser treatment or the absence of reflux despite the recanalization of the proximal segment of the vessel. Furthermore, independently of clinically evident varicosities, failure was defined as the complete recanalization of the saphenous trunk with or without reflux in the accessory GSV, thigh perforator vein (Dodd's perforator) insufficiency, and recanalization of the proximal saphenous trunk. Also, neoreflux in the accessory saphenous vein and an increase in the diameter of the leg portion of the GSV with the recurrence of varicosities, even after successful obliteration of the saphenous trunk, were both considered signs of the progression of venous disease.

\section{Results}

Overall, 274 patients (280 limbs) underwent ELT associated with phlebectomies of the evident varicosities. The mean duration of follow up was $26.58 \pm 5.7$ months (range, 1-60). Six patients (six limbs) were excluded from the final analysis because they did not return for follow-up assessment. A recurrence of varicose veins was recorded in 30 cases $(10.9 \%)$. Echo color Doppler demonstrated GSV recanalization in 13 patients $(4.7 \%)$; recurrent varicose veins occurred in three cases $(1.1 \%)$, due to neoreflux in the anterior accessory saphenous vein and in 14 cases $(5.1 \%)$, due to insufficiency of the perforating veins.

Long-term success (according to the criteria described above) was achieved in 261 cases (95.2\%), and treatment failure was observed in 13 cases. No major complications, such as deep vein thrombosis, perforation of veins, or skin burns, occurred. Paresthesia developped in six patients: in two cases, this was transient, with symptoms resolving after 1 month; in four cases, this persisted for 6 months after the operation.

Between postoperative days 7 and 10, perivenous inflammatory processes with lymphangitic features in the middle third of the thigh developed in ten patients. These complications resolved with local therapy within 30 days of the procedure.

In eight $(61.5 \%)$ of the 13 patients with recurrent varicose veins due to GSV recanalization, secondary treatment, by 
US-guided sclerotherapy with sodium 3\% tetradecylsulfate or $3 \%$ polidocanol foam, obtained good immediate results. One patient underwent primary crossectomy plus short stripping 1 year after ELT. We successfully treated another patient with a secondary ELT about 6 months after the first laser treatment. Secondary treatment was not necessary in three cases because the symptoms regressed after laser treatment. Three patients with recurrent varicose veins due to a refluxing accessory anterior saphenous vein underwent crossectomy plus phlebectomy, with good results.

Twelve out of 14 patients with recurrence due to perforating veins in the leg underwent sclerotherapy only for varicosities, while two patients were asymptomatic and were not treated. In three of the patients who received US-guided sclerotherapy, the secondary procedure failed due to recanalization of the treated vein. These patients ultimately underwent open surgery (crossectomy plus short stripping).

\section{Conclusion}

Long-term US surveillance underscores the importance of proper patient selection for ELT, to obtain optimal therapeutic outcome, comparable with those in literature. ${ }^{7-12}$ Furthermore, US surveillance has provided evidence that the delivery of endovenous fluence equivalent greater than $70-80 \mathrm{~J} / \mathrm{cm}^{2}$ is correlated with a lower recanalization rate. ${ }^{13-15}$ Early follow up with US is mandatory to exclude major complications, such as deep vein thrombosis or perforation of the vein. Moreover, late follow up is also important, to distinguish between recurrences caused by GSV recanalization from those induced by neoreflux in the anterior accessory saphenous vein or by insufficiency of the perforating veins.

During short- and long-term follow up, the criteria for defining the procedure success should be differentiated in sonographic and clinical parameters. Favorable treatment outcome is determined not only by the presence or absence of recurrent varicosities, but also by patient satisfaction and the improvement of symptoms attributable to venous insufficiency.

\section{Disclosure}

The authors report no conflicts of interest in this work.

\section{References}

1. Min RJ, Khilnani N, Zimmet SE. Endovenous laser treatment of saphenous vein reflux: long-term results. J Vasc Interv Radiol. 2003;14(8):991-996.

2. Stirling M, Shortell CK. Endovascular treatment of varicose veins. Semin Vasc Surg. 2006;19(2):109-115.

3. Lin JC, Peterson EL, Rivera ML, Smith JJ, Weaver MR. Vein mapping prior to endovenous catheter ablation of the great saphenous vein predicts risk of endovenous heat-induced thrombosis. Vasc Endovascular Surg. 2012;46(5):378-383.

4. Corcos L, Dini S, Peruzzi G, Pontello D, Dini M, De Anna D. Duplex ultrasound changes in the great saphenous vein after endosaphenous laser occlusion with 808-nm wavelength. J Vasc Surg. 2008;48(5):1262-1271.

5. Myers KA, Jolley D. Outcome of endovenous laser therapy for saphenous reflux and varicose veins: medium-term results assessed by ultrasound surveillance. Eur J Vasc Endovasc Surg. 2009;37(2):239-245.

6. Theivacumar NS, Dellagrammaticas D, Beale RJ, Mavor AI, Gough MJ. Factors influencing the effectiveness of endovenous laser ablation (EVLA) in the treatment of great saphenous vein reflux. Eur $J$ Vasc Endovasc Surg. 2008;35(1):119-123.

7. Desmyttère J, Grard C, Wassmer B, Mordon S. Endovenous 980-nm laser treatment of saphenous veins in a series of 500 patients. $J$ Vasc Surg. 2007;46(6):1242-1247.

8. Min RJ, Khilnani NM. Endovenous laser ablation of varicose veins. J Cardiovasc Surg (Torino). 2005;46(4):395-405.

9. Agus GB, Mancini S, Magi G; IEWG. The first 1000 cases of Italian Endovenous-laser Working Group (IEWG). Rationale, and long-term outcomes for the 1999-2003 period. Int Angiol. 2006;25(2):209-215.

10. Samuel N, Wallace T, Carradice D, Mazari FA, Chetter IC. Comparison of $12-\mathrm{w}$ versus $14-\mathrm{w}$ endovenous laser ablation in the treatment of great saphenous varicose veins: 5-year outcomes from a randomized controlled trial. Vasc Endovascular Surg. 2013;47(5):346-352.

11. Sadek M, Kabnick LS, Berland T, et al. Update on endovenous laser ablation: 2011. Perspect Vasc Surg Endovasc Ther. 2011;23(4): 233-237.

12. Spreafico G, Kabnick L, Berland TL, et al. Laser saphenous ablations in more than 1,000 limbs with long-term duplex examination follow-up. Ann Vasc Surg. 2011;25(1):71-78.

13. Kavuturu S, Girishkumar H, Ehrlich F. Endovenous laser ablation of saphenous vein is an effective treatment modality for lower extremity varicose veins. Am Surg. 2006;72(8):672-675; discussion 675-676.

14. Rasmussen LH, Bjoern L, Lawaetz M, Blemings A, Lawaetz B, Eklof B. Randomized trial comparing endovenous laser ablation of the great saphenous vein with high ligation and stripping in patients with varicose veins: short-term results. J Vasc Surg. 2007;46(2):308-315.

15. Proebstle TM, Moehler T, Herdemann S. Reduced recanalization rates of the great saphenous vein after endovenous laser treatment with increased energy dosing: definition of a threshold for the endovenous fluence equivalent. J Vasc Surg. 2006;44(4):834-839.

Journal of Vascular Diagnostics

\section{Publish your work in this journal}

Journal of Vascular Diagnostics is an international, peer-reviewed journal of diagnostics, focusing on non invasive vascular investigation methods involved in the evaluation of vascular diseases. The journal is committed to the rapid publication in the fields of vascular diseases. Original research, review, case reports, expert opinion and

Dovepress

commentaries are all considered for publication. The manuscript management system is completely online and includes a very quick and fair peer-review system, which is all easy to use. Visit http://www.dovepress. $\mathrm{com} /$ testimonials.php to read real quotes from published authors. 